\title{
Maternal antecedents of adiposity and studying the transgenerational role of hyperglycemia and insulin (MAASTHI): a prospective cohort study
}

\section{Protocol of birth cohort at Bangalore, India}

Giridhara R. Babu ${ }^{1 *}$ D, GVS Murthy ${ }^{2,3}$, R. Deepa ${ }^{4}$, Yamuna ${ }^{4}$, Prafulla ${ }^{4}$, H. Kiran Kumar ${ }^{4}$, Maithili Karthik', Keerti Deshpande ${ }^{4}$, Sara E. Benjamin Neelon ${ }^{5,6}$, D. Prabhakaran ${ }^{7,8,9,10}$, Anura Kurpad ${ }^{11,12,13,14}$ and Sanjay Kinra ${ }^{15}$

\begin{abstract}
Background: India is experiencing an epidemic of obesity-hyperglycaemia, which coincides with child bearing age for women. The epidemic can be sustained and augmented through transgenerational transmission of adiposity and glucose intolerance in women. This presents an opportunity for exploring a clear strategy for the control of this epidemic in India. We conducted a study between November 2013 and May 2015 to inform the design of a large pregnancy cohort study. Based on the findings of this pilot, we developed the protocol for the proposed birth cohort of 5000 women, the recruitment for which will start in April 2016. The protocol of the study documents the processes which aim at advancing the available knowledge, linking several steps in the evolution of obesity led hyperglycemia.

Methods: Maternal Antecedents of Adiposity and Studying the Transgenerational role of Hyperglycemia and Insulin (MAASTHI) is a cohort study in the public health facilities in Bangalore, India. The objective of MAASTHI is to prospectively assess the effects of glucose levels in pregnancy on the risk of adverse infant outcomes, especially in predicting the possible risk markers of later chronic diseases. The primary objective of the proposed study is to investigate the effect of glucose levels in pregnancy on skinfold thickness (adiposity) in infancy as a marker of future obesity and diabetes in offspring. The secondary objective is to assess the association between psychosocial environment of mothers and adverse neonatal outcomes including adiposity. The study aims to recruit 5000 pregnant women and follow them and their offspring for a period of 4 years. The institutional review board at The Indian Institute of Public Health (IIPH)-H, Bangalore, Public Health Foundation of India has approved the protocol. All participants are required to provide written informed consent.

(Continued on next page)
\end{abstract}

\footnotetext{
* Correspondence: giridhar@iiphh.org

${ }^{1}$ Wellcome Trust-DBT India alliance Intermediate Research Fellow in Public

Health, Additional Professor, Public Health Foundation of India (PHFI), IIPH-H,

Bangalore campus, SIHFW premises, Beside leprosy hospital, 1st cross,

Magadi road, Bangalore 560023, India

Full list of author information is available at the end of the article
} 
(Continued from previous page)

Discussion: The findings from this study may help to address important questions on screening and management of high blood sugar in pregnancy. It may provide critical information on the specific determinants driving the underweight-obesity-T2DM epidemic in India. The study can inform the policy regarding the potential impact of screening and management protocols in public healthcare facilities. The public health implications include prioritising issues of maternal glycemic control and weight management and better understanding of the lifecourse determinants in the development of T2DM.

Keywords: Gestational diabetes, Hyperglycemia, Obesity, Birth cohort, Protocol, Lifecourse epidemiology

\section{Background}

India is facing an epidemic of Type II Diabetes Mellitus (T2DM) with 69.2 million people with diabetes in 2015 [1]. This prevalence rate is projected to increase to 87 million in 2030. [2] T2DM affects Indians earlier than developed countries, [2-7] and yet there is limited research to elucidate the causal mechanisms. Part of this high burden may be explained by programming of T2DM and obesity ensuing in early life [8-12]. Hyperglycemia in pregnant women may alter the intrauterine environment, thereby increasing the risk of obesity in childhood and their future risk of diabetes.[2, 12-19] With an estimated $16.9 \%$ of pregnant women affected [13], approximately 6 million women might be suffering from hyperglycemia in pregnancy in India $[1,20]$. The severity and form of maternal hyperglycemia may have a distinct role in the development of childhood obesity and T2DM in adult life $[19,21-23]$. It is important to recognize the specific deleterious outcomes which may manifest in children, including effects of maternal carbohydrate intolerance at all levels including near normal levels [16, 24-27]. Understanding this pathway could help address the underweight and gestational hyperglycemia led obesity epidemic in low- and middle-income countries (LMICs) like India.

Hyperglycemia and Adverse Pregnancy Outcome (HAPO) study confirmed the link between maternal glucose and neonatal adiposity and suggested that the relationship might be mediated by fetal insulin production. [27-30]. From the lifecourse perspective, the epistemology for the gestational hyperglycemia obesity led epidemic has been implied by three important hypotheses. The 'fuel mediated teratogenesis' hypothesis [27, 30] states that in-utero exposure to maternal hyperglycaemia can result in fetal hyperinsulinaemia [8, 27, 30-32]. The 'thrifty phenotype' hypothesis suggests that adaptive mechanisms due to child undernutrition may result in T2DM epidemic in LMICs [4]. The 'thrifty genotype' hypothesis infers that conservatory mechanisms at the level of the genotype can occur in populations that have undergone a sudden transition from undernutrition to overnutrition [9]. The 'thrifty insulin hypothesis' forms a part of this, which states that low birth weight and
T2DM are two phenotypes of the same genotype and also predict insulin resistance [9]. The initial evidence for these hypotheses is provided by the Parthenon Birth cohort and similar studies [19, 33-35].

Urbanization-led changes in Indians with contributions from unique genotype and phenotype is likely contributing to the epidemic of obesity-hyperglycaemia. India is experiencing a rise in prevalence of adiposity and glucose intolerance at younger ages, which coincides with child bearing age for women [30]. The later stages of the epidemic could then be sustained and augmented by a feed forward mechanism, through transgenerational transmission of adiposity and glucose intolerance in women [36-38]. This presents an opportunity for exploring a clear strategy for the control of this epidemic in India through rigorous screening and management of adiposity and glucose intolerance in pregnancy.

Between November 2013 and May 2015, we conducted a pilot to inform the design of a large pregnancy cohort study that could reliably test some aspect of the abovementioned hypotheses. The protocol of the initial study and the baseline results have already been published [39]. Based on the findings of this pilot, we developed the protocol for the proposed pregnancy cohort of 5000 women, the recruitment for which began in April 2016. The protocol of the study documents the processes which aim at advancing the available knowledge, linking several steps in the evolution of T2DM.

\section{Methods/design}

Aim and objectives

The aim of this study is to prospectively assess the effects of glucose levels in pregnancy on the risk of adverse infant outcomes, especially in predicting the possible risk markers of later chronic diseases (Fig. 1). The primary objective of the proposed study is to investigate the effect of glucose levels in pregnancy on skinfold thickness (adiposity) in infancy as a marker of future obesity and diabetes in offspring. Because psychosocial environment could itself be an important independent predictor of adiposity and could confound its relationship with maternal hyperglycaemia, our secondary objective is to assess the association between psychosocial environment of mothers and adverse neonatal 


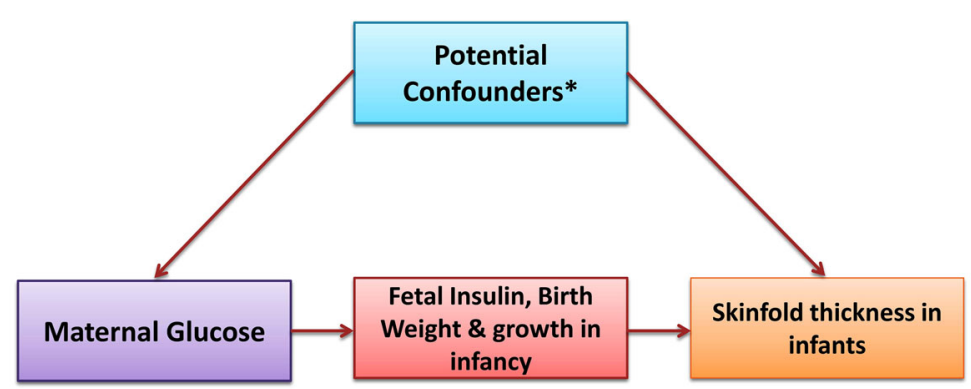

Potential confounders*: Age, BMI, Family history of diabetes, gestational age, parity, post medical history, family history of hypertension, social support, lifestyle factors and socioeconomic status.

Fig. 1 Conceptual Directional Acyclic Graph (DAG) depicting the hypothesis 1. Maternal glucose in pregnancy is associated with skinfold thickness (adiposity) of offspring at one year

outcomes including adiposity. The specific exposure, outcome and potential confounders for these objectives are listed in Table 1.

\section{Hypotheses:}

1. Maternal glucose in pregnancy is associated with skinfold thickness (adiposity) of offspring at one year (Fig. 1)

2. Psychosocial environment measured by social support and distress is related to skinfold thickness of offspring at one year (Fig. 2)

For hypotheses 1, the exposure of interest is maternal blood glucose level. We are not examining gestational diabetes only, but are interested in exploring the effect of the continuous range of glucose as exposure from near normal ranges to hyperglycemia.

After the fasting blood sample is drawn, the pregnant woman will receive $75 \mathrm{~g}$ oral glucose load and a venous blood sample will be collected 2 hours later for estimating plasma glucose [40-42]. Evaluation of the samples will be done through the central laboratory so as to minimize the confounding effects of analytic variation. The primary outcome of our study is skinfold thickness in infants as a measure of adiposity. Skinfold thickness is the most accurate method of measuring body fat rather than Body Mass Index (BMI) as this will provide a better indication of individual fat and risk of obesity. Skinfold thickness measurement is a traditional and reliable measure of fat percentage. From research it's found that greater weight gain during pregnancy was associated with higher child's body mass index, sum of triceps and subscapular skinfold thickness [43, 44]. The triceps, biceps and subscapular skinfolds will be measured as described by Tanner/Whitehouse using a Holtain Calipers (Holtain, U.K.). Triceps skin folds will be measured over the posterior belly of triceps muscle of the left arm, halfway between the acromion and the olecranon, on a line passing upwards from the olecranon in the axis of the limb, with the arm extended. Subscapular skinfold will be measured immediately below the angle of the left scapula, in the natural cleavage line of the skin, with the arm held by the side of the body. In addition, we will also assess weight for length and waist girth (in centimeters) as co-primary outcomes. Waist girth is measured by placing the tape around the abdomen immediately above the umbilicus ensuring that it is horizontal and marked at the end of expiration. The ultrasound scan records of the respondents are reviewed and the estimated foetal weight, biparietal diameter (BPD), head circumference (HC), abdominal circumference (AC), femur length (FL) is recorded. Mother's weight and skinfold thickness are measured during antenatal period. Based on the literature, we have identified the following potential confounders based on a priori knowledge: age, BMI, family

Table 1 The exposure, outcome and potential confounders for the study objectives

\begin{tabular}{lll}
\hline Exposure & Outcome & Potential confounders \\
\hline Maternal glucose level & $\begin{array}{l}\text { Skinfold thickness in infants } \\
\text { at one year }\end{array}$ & $\begin{array}{l}\text { Age, body mass index (BMI), family history of diabetes, } \\
\text { gestational age, parity, past medical history, family history } \\
\text { of hypertension and socio-economic status }\end{array}$ \\
Psychosocial environment & $\begin{array}{l}\text { Skinfold thickness in infants } \\
\text { at one year }\end{array}$ & $\begin{array}{l}\text { Maternal age, parity, BMl, weight-gain during pregnancy } \\
\text { on fetal biometry measures, diet, gestational age, lifestyle } \\
\text { factors, alcohol and tobacco use }\end{array}$ \\
\hline
\end{tabular}




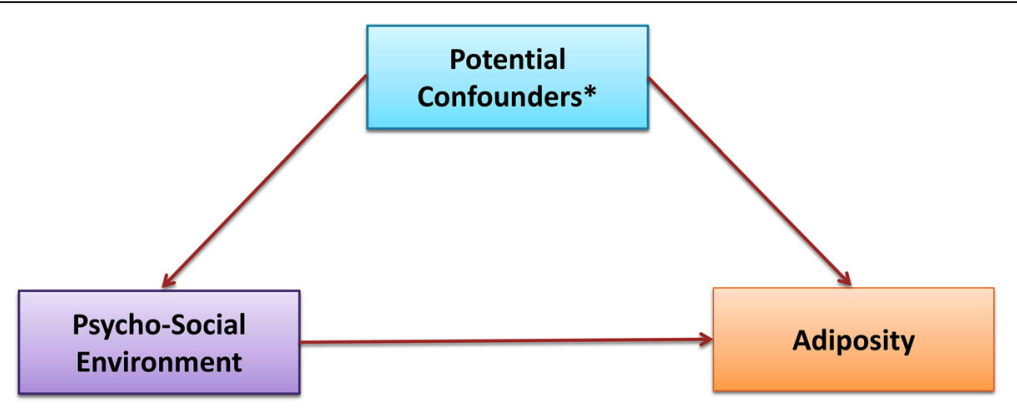

Potential Confounders*:- Maternal age, parity, BMI, weight gain during pregnancy on fetal biometry measures, diet, gestational age, lifestyle factors, alcohol and tobacco use

Fig. 2 Conceptual Directional Acyclic Graph (DAG) depicting the hypothesis 2. Psychosocial environment measured by social support and distress is related to skinfold thickness of offspring at one year

history of diabetes, gestational age, parity, past medical history, family history of hypertension and socioeconomic status.

For hypotheses 2, the exposure of interest is social support, measured by means of a validated tool (Questionnaire) administered during second trimester of pregnancy. Social support to the mother will be measured using a questionnaire developed at St. John's Research Institute to evaluate a broad range of social support (i.e., emotional, instrumental, informational, and appraisal) [45]. The Edinburgh Postnatal Depression Scale is administered to the respondents during pregnancy, after delivery and when the infant is 14 week old. Those who score greater than 13 in the EPDS scale are administered Global Mental Health Assessment Tool (GMHAT) for further diagnosis and are referred to the psychiatrist at the hospital for counselling and treatment. The outcome of interest is infant adiposity. The potential confounders include maternal age, parity, BMI, weight gain during pregnancy on fetal biometry measures, [46] diet, gestational age, lifestyle factors, and alcohol and tobacco use [46, 47]. The mother's 24 hour diet recall is recorded during pregnancy. The infant's feeding mode whether it is breastfed, time of first breast feed and exclusive breastfeeding at birth, duration of breastfeeding and complementary feeding practices for every child is recorded annually. In addition, we may include additional potential confounders in the models based on emerging literature.

\section{Sample size and Study centers}

Assuming an incidence of $5 \%$ obesity in children born to mothers with euglycemia, [48, 49] and a relative risk of 1.5 in the hyperglycaemic group, our estimated sample size for $80 \%$ power to detect a difference at a $95 \%$ confidence level, is 2936. Further assuming a loss to follow-up of up to $60 \%$, we plan to recruit 5000 women. The assumed loss to follow up is comparable to another birth cohort followed up at a similar age in India
(Mysore Parthenon birth cohort); however unlike cohorts recruited from the community, ours is a hospital based study with outcome assessment at routine immunisation visits during infancy which are generally well attended, we expect the eventual loss to follow up to be much lower in our study [50]. We have obtained approval to conduct the study at Jayanagar General Hospital, a 300 bedded hospital. In addition, the city municipal corporation (Brihat Bengaluru Mahanagara Palike : BBMP) governing the greater Bangalore metropolitan area has provided approval for public hospitals in the city to participate in the study. The study is initiated at Jayanagar General Hospital; the hospital registers around 200-400 new cases of pregnant women each month.

\section{Eligibility criteria}

All pregnant women between the age of 18-45 years who are less than 32 weeks of gestation and a) plan to deliver in the study hospital and b) reside in the study area will be eligible for recruitment. The recruitment will be done after obtaining an informed consent and noting relevant socio-demographic details. The exclusion criteria includes history of diabetes, Hepatitis B infection, HIV positivity and inability to complete the oral glucose-tolerance test within 32 weeks of gestation.

\section{Recruitment and follow-up}

The process of recruitment, follow-up and corresponding timelines in the cohort have been captured in the Fig. 3. Pregnant women with a gestational period of less than 32 weeks will be recruited. A baseline questionnaire will be administered that includes socio-economic status, Standard of Living Index, 24-hour dietary recall, dietary habits, physical activity, obstetrics history, psychosocial stressors and social support. Weight, height, sitting height, skinfold thickness of biceps, triceps and subscapular skinfold will be recorded (Table 2). Blood pressure will be 


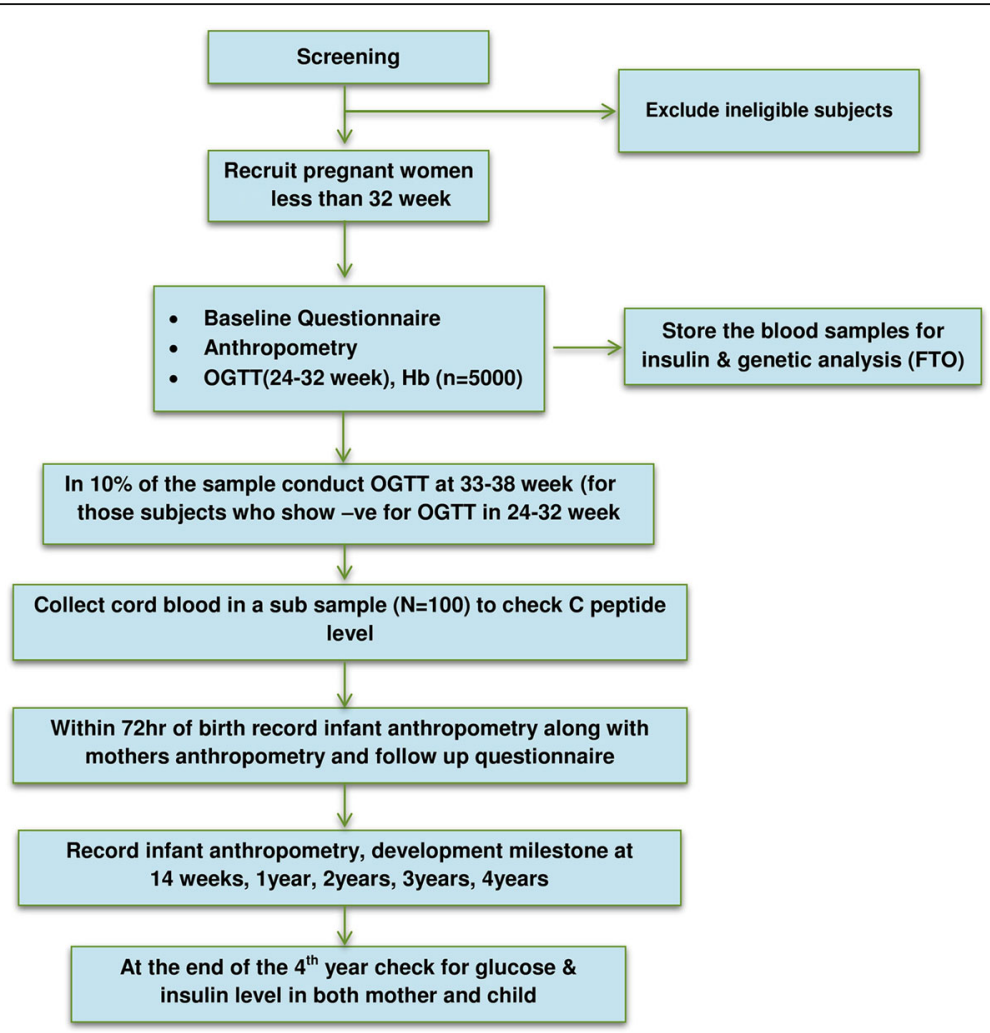

Fig. 3 Flow Diagram depicting the steps in cohort study. The whole process of screening of eligible pregnant women for OGTT, recruitment and follow-up at the end of $4^{\text {th }}$ year has depicted in this flow diagram

measured using an automated BP apparatus. All women will undergo an OGTT at 24 to 32 weeks of gestation. They will be asked to fast for a minimum $8 \mathrm{~h}$ prior to the study visit, where fasting samples will be drawn. Subsequently, $75 \mathrm{~g}$ of glucose will be given and the postprandial sample will be drawn after two hours. In a sub-sample of pregnant women who have normal ranges of glucose in the second trimester, another OGTT at 33 to 38 weeks will be performed to explore the proportion of women who develop gestational diabetes in the later phase of the third trimester. In a sub-sample, HbA1c test will also be conducted based on age, BMI, family history of diabetes and parity. Maternal subcutaneous fat is a significant predictor of adverse pregnancy outcomes. The visceral and subcutaneous fat thickness around abdomen through ultrasound scan will be obtained. A trained sonographer will be performing the scan and strict measures will be taken to avoid gender determination. Visceral fat builds up between and around internal organs such as the stomach and intestines, and produces toxins that make the body resistant to insulin. Subcutaneous fat is found just beneath the skin, and total fat is the combination of visceral and subcutaneous fat. Depending on presence in hospital visits, the husband's anthropometry and blood pressure will also be recorded.

The measurements on skinfold thickness and weight for length in infants will be taken at birth and at 14 weeks corresponding to the visit of the mother and child for the purpose of immunization. These measurements will be repeated once in every year for the remaining duration of the study. Follow-up at 1, 2, 3 and 4 years will be on the child's birthday for all children. At the end of the 4 years of follow up, the glucose and insulin levels in children and mother will be tested (Fig. 3).

\section{Quality control}

For questionnaires and anthropometric measurements, field team will be trained using strict protocols and the accuracy and interobserver and intraobserver reliability of their measurements assessed at the outset and every 6 months. Anthropometric equipment will be calibrated monthly and recordings logged. Biochemical assays carried out by a single laboratory will be quality assured by India's National Accreditation Board for Testing and Calibration Laboratories (NABL). Quality control samples will be collected for the internal and external quality checks. 
Table 2 Anthropometry and ultrasound measurements in mother and child

\begin{tabular}{ll}
\hline Time & Test \\
\hline 24-32 weeks & $\begin{array}{l}\text { Blood pressure of mother (Automatic BP } \\
\text { apparatus) }\end{array}$ \\
& Anthropometry of mother \\
& Weight \\
& Height \\
& Sitting Height \\
& Biceps skinfold \\
& Triceps skinfold \\
& Subscapular skinfold \\
& Head circumference \\
Subsample of pregnant women $(N=500):$ \\
Visceral and subcutaneous fat thickness \\
around abdomen. \\
Antrasound in pregnanthometry of child \\
At birth, 14 ${ }^{\text {th }}$ week and \\
then annually & Weight \\
& Length \\
& Crown rump length \\
& Head circumference \\
& Chest circumference \\
& Waist circumference \\
& Hip circumference \\
& Biceps skinfold \\
& Triceps skinfold \\
& Subscapular skinfold \\
&
\end{tabular}

\section{Data collection}

Structured questionnaires will be administered by trained interviewers for baseline assessment and followup. Data will be entered directly using tablet devices provided to the field staff with validation checks built in to minimise data entry errors. Trained phlebotomists will collect blood samples. Participants not attending follow-ups will be reminded through linkages with frontline health workers in the community.

\section{Laboratory analysis and sample storage}

We will collect $11 \mathrm{ml}$ fasting venous blood sample and $2 \mathrm{ml}$ postprandial sample $2-\mathrm{h}$ after following a $75 \mathrm{~g}$ oral load of glucose for the laboratory investigations. The fasting sample will be collected in plain, EDTA and sodium fluoride vacutainers for storage, haemoglobin and glucose assays respectively. Blood samples will be centrifuged and transferred within an hour in cool boxes to a single central laboratory for assays with external quality assurance mechanisms in place. Relevant study assays will be carried out at each time point (Table 3) and remaining sample stored in aliquots for future analysis.

\section{Data management and analysis plan Data analysis}

Descriptive analysis will be done to summarize sample characteristics using frequency and percentage. The associations of interest for primary and secondary hypotheses will be assessed using multivariate regression analyses treating skinfold thickness as a continuous outcome as obesity is hard to define at this age, with and without adjustments for potential confounders. For multivariate analyses, variable selection will be based

Table 3 List of laboratory tests, sample size and proposed biomarkers in the study

\begin{tabular}{|c|c|c|c|}
\hline Time/Sample & Test & $\mathrm{N}$ & Biomarker \\
\hline \multirow{7}{*}{$\begin{array}{l}\text { Pregnant women } \\
\text { between 24-32 weeks }\end{array}$} & Blood pressure (automated) & 5000 & \\
\hline & $\begin{array}{l}\text { OGTT (Fasting plasma glucose, } 2 \text { Hour Postprandial } \\
\text { plasma glucose) }\end{array}$ & 5000 & Glucose \\
\hline & Haemoglobin & 5000 & Haemoglobin \\
\hline & HbA1c (glycosylated haemoglobin, Type A1C) & 500 & Glycosylated haemoglobin \\
\hline & $\begin{array}{l}\text { One aliquot of fasting sample will be frozen at }-80^{\circ} \mathrm{C} \\
\text { for measurement of serum insulin }\end{array}$ & 1000 & $\begin{array}{l}\text { Insulin resistance and insulin secretion through } \\
\text { homeostasis model assessment (HOMA) }\end{array}$ \\
\hline & Blood sample to be preserved at $-80^{\circ} \mathrm{C}$ & 5000 & Micronutrients, DNA and protein markers \\
\hline & $\begin{array}{l}\text { Repeat OGTT after } 32 \text { weeks (Fasting plasma glucose, } 2 \\
\text { Hour Postprandial plasma glucose) }\end{array}$ & 500 & $\begin{array}{l}\text { To explore those who develop gestational diabetes } \\
\text { after } 32 \text { weeks }\end{array}$ \\
\hline Cord blood & C-peptide & 100 & Insulin \\
\hline Fathers & Fasting blood glucose in fathers & 500 & Glucose \\
\hline $\begin{array}{l}\text { Mothers (During follow } \\
\text { up visits) }\end{array}$ & Random blood glucose & 5000 & Glucose \\
\hline $\begin{array}{l}\text { At the end of the study } \\
\text { (IV year) }\end{array}$ & $\begin{array}{l}\text { Fasting blood glucose and insulin levels in mother } \\
\text { and child }\end{array}$ & 5000 & Glucose \\
\hline
\end{tabular}


primarily on prior knowledge (a priori) and also the outcome of crude analysis. Variables with $p$-values $>0.10$ in the univariate analysis will be included in the multivariate analysis. Possible interactions will also be explored by including product terms in the model [51]. For continuous-variable analyses, odds ratios will be calculated for a 1-SD increase in fasting and 2-h plasma glucose levels. Sum of skin folds $>90$ th percentile will be determined for term deliveries based on gender with adjustment for gestational age and parity $(0,1$, and $2+)$. A detailed plan for data analysis is provided in the Additional file 1.

\section{Discussion}

The findings from this study may help to address important questions on screening and management of high blood sugar in pregnancy. It may provide critical information on the specific determinants driving the underweight-obesity-T2DM epidemic in India, particularly when the data is considered together with data from other cohorts such as the Mysore Parthenon Study, which collected data when India was at an earlier stage of its nutrition transition. In addition it may provide data on appropriate values of cut-offs for healthy glucose levels in pregnancy in India, as well as explorations of role of maternal nutritional status, confounding by psychosocial environment and other determinants.

There can be significant public health implications of the study. First, due to implementation in public health facilities, the results could directly inform the potential impact of scaling up stronger screening and management protocols in the future. Second, the results can position the issues of maternal glycemic control and weight management (both underweight and obesity) to the core of policy agenda. Third, the results may suggest lifestyle modifications in both women and children to prevent and postpone the development of T2DM.

\section{Additional file}

Additional file 1: A detailed plan for data analysis. Conceptual DAG for data analysis and Model-based analysis. (DOCX $133 \mathrm{~kb}$ )

\section{Abbreviations}

AC: Abdominal circumference; BBMP: Brihat Bengaluru Mahanagara Palike BMI: Body Mass Index; BPD: Biparietal diameter; EDTA: Ethylene Diamine Tetra Aceticacid; EPDS: Edinburgh Postnatal Depression Scale;

GDM: Gestational diabetes mellitus; GH: Gestational hyperglycaemia; GMHAT: Global Mental Health Assessment Tool; HAPO: Hyperglycemia and adverse pregnancy outcome study; HC: Head circumference; HIV: Human immunodeficiency virus; HOMA: Homeostasis model assessment; IIPH: Indian Institute of Public Health; LMIC: Low- and middle-income countries; MAASTHI: Maternal antecedents of adiposity studying the transgenerational role of hyperglycaemia and insulin; NABL: National Accreditation Board for Testing and Calibration Laboratories; OGTT: Oral glucose tolerance test; SD: Standard Deviation; T2DM: Type 2 diabetes mellitus; WHO: World Health Organization

\section{Acknowledgements}

Our sincere thanks to the Medical Superindentent Dr B.S. Lokesh, doctors and staff at Jayanagar General Hospital, Bangalore for the ongoing study. We thank Dr Ramadevi, Jayanagar General Hospital for facilitating the study coordination. We thank Dr. Sumathi Swaminathan and Dr Pratiba Dwarkanath, Division of Nutrition, St John's Research Institute (SJRI) who provided insight and expertise that greatly assisted the study. We are also immensely grateful to Dr GV Krishnaveni and Dr Murali Krishna from CSI Holdsworth Memorial Hospital for sharing their vast knowledge and experience in setting up the larger cohort study. We would like to acknowledge the constant support of the research staff of St John's Research Institute and CSI Holdsworth Memorial Hospital, Mysore in providing us their valuable feedback. Our sincere thanks to the Chief Health Officer of Bruhat Bengaluru Mahanagara Palike (BBMP) and the staff of Banashankari Referral Hospital and H Siddaiah Road Referral Hospital for helping us in conducting the feasibility study. We sincerely thank Dr's Prashanth Thankachan, Rajath Athreya, Sucheta Bhagat, Prasanna Kumar and Ruby Gupta for their valuable technical inputs. We thank Dr. Suresh Shapeti and T.S. Ramesh for facilitating administrative approvals and coordination.

\section{Funding}

The MAASTHI cohort is funded by an Intermediate Fellowship by the Wellcome Trust DBT India Alliance (Clinical and Public Health Research Fellowships).

\section{Availability of data and materials}

Requests for the datasets generated during and/or analyzed during the current study can be directed to the corresponding author. The Institutional ethics committee reviewing at IIPH-Bangalore will decide on providing the data.

\section{Authors' contributions}

GRB is the principal investigator of this study and is awarded the intermediate fellowship from Wellcome Trust DBT India alliance. He has conceptualized, written and has taken the lead in completing manuscript through all stages of preparation and submission till publication and is the first author. GVS has reviewed the application from the conceptualization stage and has contributed to each version of the manuscript. DR, YA, PS, KK, MK, KD are members of MAASTHI research team who have contributed to each version of the revision and participated in the conduct of the study. Their role as authors is listed based on their contribution to the content, quality, and revision of the manuscript. SBN, PD and AK have authorship depending on their contribution to paper. SK has reviewed the application from the conceptualization stage and has contributed to each version of the manuscript. All authors have contributed to the article critically for important intellectual content and final approval of the version to be published.

\section{Competing interests}

The authors declare that they have no competing interests.

\section{Consent for publication}

Not applicable.

\section{Ethics approval and consent to participate}

The study was reviewed and approved by the institutional ethical review board (IEC) at Bangalore campus of IIPH-H (Approval number IIPHHB-TRCIEC091-2015, dated $13^{\text {th }}$ November 2015). Only participants willing to participate voluntarily and those who have provided written informed consent are enrolled.

\footnotetext{
Author details

${ }^{1}$ Wellcome Trust-DBT India alliance Intermediate Research Fellow in Public Health, Additional Professor, Public Health Foundation of India (PHFI), IIPH-H, Bangalore campus, SIHFW premises, Beside leprosy hospital, 1st cross, Magadi road, Bangalore 560023, India. Indian Institute of Public Health-Hyderabad, Plot \# 1, A.N.V. Arcade, Amar Co-op Society, Kavuri Hills, Madhapur, Hyderabad 500033, India. ${ }^{3} \mathrm{ICEH}$, London School of Hygiene \& Tropical Medicine, 3rd Floor, South Courtyard, Keppel Street, London WC1E 7HT, UK. ${ }^{4}$ Research team of MAASTHI, Public Health Foundation of India, IIPH-H, Bangalore campus, SIHFW premises, Beside leprosy hospital, 1st cross, Magadi road, Bangalore 560023, India. ${ }^{5}$ Johns Hopkins Bloomberg School of
} 
Public Health, 624 N Broadway, Hampton House 755, Baltimore, MD 21205, USA. ${ }^{6}$ Centre for Diet and Activity Research, MRC Epidemiology, University of Cambridge, Cambridge, UK. ${ }^{7}$ Centre for Control of Chronic Conditions (CCCC, Public Health Foundation of India (PHFI), New Delhi, India. ${ }^{8}$ Centre for Chronic Disease Control (CCDC), New Delhi, India. ${ }^{9}$ Department of Epidemiology, London School of Hygiene and Tropical Medicine, London WC1E 7HT, UK. ${ }^{10}$ Emory Rollins School of Public Health, 1518 Clifton Rd, Atlanta GA 30322, USA. ${ }^{11}$ Nutrition Division, St John's Research Institute, Bangalore, India. ${ }^{12}$ Nutrition Society of India, National Institute of Nutrition Campus, Hyderabad 500 007, India. ${ }^{13}$ IAEA Collaborating Centre for Stable Isotope Technologies in Nutrition, St John's Research Institute, Bangalore, India. ${ }^{14}$ International Nutrition Foundation Protein Advisory Group and Chair, Expert Committee on Obesity, ICMR, New Delhi, India. ${ }^{15}$ Reader in Clinical Epidemiology \& Honorary Consultant in Paediatric Obesity - London School of Hygiene \& Tropical Medicine \& University College London Hospital, London, UK.

Received: 5 July 2016 Accepted: 22 September 2016

Published online: 14 October 2016

\section{References}

1. Federation ID: IDF Diabetes Atlas. International Diabetes Federation,7th edn Brussels, Belgium 2015

2. Shaw JE, Sicree RA, Zimmet PZ. Global estimates of the prevalence of diabetes for 2010 and 2030. Diabetes Res Clin Pract. 2010;87(1):4-14.

3. Prasad A. Type 2 diabetes mellitus in young: need for early screening. Indian Pediatr. 2011;48(9):683-8.

4. Hales CN, Barker DJ. The thrifty phenotype hypothesis. Br Med Bull. 2001;60(1):5-20

5. Anjana R, Pradeepa R, Deepa M, Datta M, Sudha V, Unnikrishnan R, Bhansali A, Joshi S, Joshi P, Yajnik C. Prevalence of diabetes and prediabetes (impaired fasting glucose and/or impaired glucose tolerance) in urban and rural India: Phase I results of the Indian Council of Medical Research-INdia DIABetes (ICMR-INDIAB) study. Diabetologia. 2011;54(12):3022-7.

6. Mohan V, Sandeep S, Deepa R, Shah B, Varghese C. Epidemiology of type 2 diabetes: Indian scenario. Indian J Med Res. 2007;125(3):217-30.

7. Mohan V, Amutha A, Ranjani H, Unnikrishnan R. Chapter 33. Clinical Approach to Diabetes in the Young in India. in Medicine update, Edited by A. Muruganathan. The Association of Physicians of India. 2013;23:155-61.

8. Hattersley AT, Tooke JE. The fetal insulin hypothesis: an alternative explanation of the association of low birth weight with diabetes and vascular disease. Lancet. 1999;353(9166):1789-92.

9. Neel JV. Diabetes mellitus: a "thrifty" genotype rendered detrimental by "progress"? Am J Hum Genet. 1962;14(4):353.

10. Fall CH. Non-industrialised countries and affluence relationship with type 2 diabetes. Br Med Bull. 2001:60(1):33-50.

11. Inturrisi M, Lintner NC, Sorem KA. Diagnosis and treatment of hyperglycemia in pregnancy. Endocrinol Metab Clin North Am. 2011:40(4):703-26.

12. Kjos SL, Buchanan TA. Gestational diabetes mellitus. New Engl J Med. 1999:341(23):1749-56.

13. Seshiah V, Balaji V, Balaji MS, Sanjeevi C, Green A. Gestational diabetes mellitus in India. Japi. 2004;52:707-11.

14. Tripathi R, Tolia N, Gupta VK, Mala YM, Ramji S, Tyagi S. Screening for gestational diabetes mellitus: a prospective study in a tertiary care institution of North India. J Obstet Gynaecol Res. 2012;38(2):351-7.

15. Jovanovic L, Pettitt DJ. Gestational diabetes mellitus. JAMA. 2001;286(20):2516-8.

16. Torloni M, Betrán A, Horta B, Nakamura M, Atallah A, Moron A, Valente O. Prepregnancy $\mathrm{BMI}$ and the risk of gestational diabetes: a systematic review of the literature with meta analysis. Obes Rev. 2009;10(2):194-203.

17. Jones C. Gestational diabetes and its impact on the neonate. Neonatal Netw. 2001;20(6):17-23.

18. Kim C, Newton KM, Knopp RH. Gestational diabetes and the incidence of type 2 diabetes a systematic review. Diabetes Care. 2002;25(10):1862-8.

19. Krishnaveni G, Hill J, Veena S, Leary S, Saperia J, Chachyamma K, Karat S, Fall C. Truncal adiposity is present at birth and in early childhood in South Indian children. Indian Pediatr. 2005;42(6):527.

20. Retnakaran R, Hanley AJ, Connelly PW, Sermer M, Zinman B. Ethnicity modifies the effect of obesity on insulin resistance in pregnancy: a comparison of Asian, South Asian, and Caucasian women. J Clin Endocrinol Metabol. 2006;91(1):93-7.
21. Whitaker RC, Dietz WH. Role of the prenatal environment in the development of obesity. J Pediatr. 1998;132(5):768-76.

22. Silverman BL, Metzger BE, Cho NH, Loeb CA. Impaired glucose tolerance in adolescent offspring of diabetic mothers: relationship to fetal hyperinsulinism. Diabetes Care. 1995;18(5):611-7.

23. Persson B, Gentz J, Möller E. Follow up of children of insulin dependent (type I) and gestational diabetic mothers. Acta Paediatr. 1984;73(6):778-84

24. Alcolado J, Thomas A. Maternally inherited diabetes mellitus: the role of mitochondrial DNA defects. Diabet Med. 1995;12(2):102-8.

25. Group HSCR. The hyperglycemia and adverse pregnancy outcome (HAPO) study. Int J Gynecol Obstet. 2002;78(1):69-77.

26. Pettitt DJ, Knowler WC. Long-term effects of the intrauterine environment, birth weight, and breast-feeding in Pima Indians. Diabetes Care. 1998;21:B138.

27. Buchanan T, Freinkel N, Lewis N, Metzger B, Akazawa S. Fuel-mediated teratogenesis. Use of D-mannose to modify organogenesis in the rat embryo in vivo. J Clin Investig. 1985;75(6):1927.

28. Group HSCR. Hyperglycemia and Adverse Pregnancy Outcome (HAPO) Study associations with neonatal anthropometrics. Diabetes. 2009;58(2):453-9.

29. Group HSCR. Hyperglycemia and adverse pregnancy outcomes. N Engl J Med. 2008;358:1991-2002.

30. Yajnik CS. Nutrient-mediated teratogenesis and fuel-mediated teratogenesis: two pathways of intrauterine programming of diabetes. Int J Gynecol Obstet. 2009;104:S27-31.

31. Fetita L-S, Sobngwi E, Serradas P, Calvo F, Gautier J-F. Consequences of fetal exposure to maternal diabetes in offspring. J Clin Endocrinol Metabol. 2006;91(10):3718-24.

32. Freinkel N. Banting Lecture 1980: of pregnancy and progeny. Diabetes. 1980;29(12):1023-35.

33. Fall C, Stein C, Kumaran K, Cox V, Osmond C, Barker D, Hales C. Size at birth, maternal weight, and type 2 diabetes in South India. Diabet Med. 1998;15(3):220-7.

34. Sobngwi E, Boudou P, Mauvais-Jarvis F, Leblanc $H$, Velho G, Vexiau P, Porcher R, Hadjadj S, Pratley R, Tataranni PA. Effect of a diabetic environment in utero on predisposition to type 2 diabetes. Lancet. 2003; 361(9372):1861-5.

35. Gillman MW, Rifas-Shiman S, Berkey CS, Field AE, Colditz GA. Maternal gestational diabetes, birth weight, and adolescent obesity. Pediatrics. 2003;111(3):e221-6.

36. Patti M-E. Intergenerational programming of metabolic disease: evidence from human populations and experimental animal models. Cell Mol Life Sci. 2013;70(9):1597-608.

37. Poston L. Intergenerational transmission of insulin resistance and type 2 diabetes. Prog Biophys Mol Biol. 2011;106(1):315-22.

38. Drake AJ, Liu L. Intergenerational transmission of programmed effects: public health consequences. Trends Endocrinol Metab. 2010;21(4):206-13.

39. Babu GR, Garadi L, Murthy G, Kinra S. Effect of hyperglycaemia in pregnancy on adiposity in their infants in India: a protocol of a multicentre cohort study. BMJ Open. 2014;4(6):e005417.

40. Seshiah V, Sahay B, Das A, Shah S, Banerjee S, Rao P, Ammini A, Balaji V, Gupta S, Divakar H. Gestational diabetes mellitus-Indian guidelines. J Indian Med Assoc. 2009:107(11):799.

41. Matsuda M, DeFronzo RA. Insulin sensitivity indices obtained from oral glucose tolerance testing: comparison with the euglycemic insulin clamp. Diabetes Care. 1999;22(9):1462-70.

42. Schmidt MI, Duncan BB, Reichelt AJ, Branchtein L, Matos MC, e-Forti AC, Spichler ER, Pousada JM, Teixeira MM, Yamashita T. Gestational diabetes mellitus diagnosed with a 2-h 75-g oral glucose tolerance test and adverse pregnancy outcomes. Diabetes Care. 2001;24(7):1151-5.

43. Oken E, Taveras EM, Kleinman KP, Rich-Edwards JW, Gillman MW. Gestational weight gain and child adiposity at age 3 years. Am J Obstet Gynecol. 2007;196(4):322. e321-322. e328.

44. Mäkelä J, Lagström H, Kaljonen A, Simell O, Niinikoski H. Hyperglycemia and lower diet quality in pregnant overweight women and increased infant size at birth and at 13months of age-STEPS study. Early Hum Dev. 2013;89(6):439-44.

45. Malda M, van de Vijver FJ, Srinivasan K, Transler C, Sukumar P, Rao K. Adapting a cognitive test for a different cultures: an illustration of qualitative procedures. Psychol Sci Q. 2008:50:451-68.

46. Diego MA, Jones NA, Field T, Hernandez-Reif M, Schanberg S, Kuhn C, Gonzalez-Garcia A. Maternal psychological distress, prenatal cortisol, and fetal weight. Psychosom Med. 2006;68(5):747-53. 
47. Feldman PJD-SC, Sandman CA, Wadhwa PD. Maternal social support predicts birth weight and fetal growth in human pregnancy. Psychosom Med. 2000;62(5):715.

48. Dabelea D. The predisposition to obesity and diabetes in offspring of diabetic mothers. Diabetes Care. 2007;30(Supplement 2):S169-74.

49. Hill JC, Krishnaveni GV, Annamma I, Leary SD, Fall CH. Glucose tolerance in pregnancy in South India: relationships to neonatal anthropometry. Acta Obstet Gynecol Scand. 2005;84(2):159-65.

50. Krishnaveni GV, Veena SR, Hill JC, Karat SC, Fall CH. Cohort profile: Mysore parthenon birth cohort. Int J Epidemiol. 2015;44(1):28-36.

51. Regnault N, Gillman MW, Rifas-Shiman SL, Eggleston E, Oken E. Sex-specific associations of gestational glucose tolerance with childhood body composition. Diabetes care 2013:DC_130333.

Submit your next manuscript to BioMed Central and we will help you at every step:

- We accept pre-submission inquiries

- Our selector tool helps you to find the most relevant journal

- We provide round the clock customer support

- Convenient online submission

- Thorough peer review

- Inclusion in PubMed and all major indexing services

- Maximum visibility for your research

Submit your manuscript at www.biomedcentral.com/submit
Biomed Central 